\title{
Monitoring tropical peat related settlement using ISBAS InSAR, Kuala Lumpur International Airport (KLIA)
} \author{
Sofie Sjögersten ${ }^{g}$ \\ a Nottingham Geospatial Institute, The University of Nottingham, Triumph Rd, Nottingham NG7 2TU, United Kingdom \\ ${ }^{\mathrm{b}}$ Department of Chemical and Environmental Engineering, The University of Nottingham, University Park, Nottingham NG7 2RD, United Kingdom \\ ${ }^{c}$ Geomatic Ventures Ltd, Nottingham Geospatial Building, Triumph Road, Nottingham NG7 2TU, United Kingdom \\ ${ }^{\mathrm{d}}$ School of Natural Sciences and Psychology, James Parsons Building, Byron Street, Liverpool, L3 3AF, United Kingdom \\ e Tropical Catchment Research Initiative (TROCARI), Malaysia \\ ${ }^{\mathrm{f}}$ University of Nottingham, Malaysia Campus, School of Biosciences, Jalan Broga, 43500 Semenyih, Selangor, Darul Ehsan, Malaysia \\ ${ }^{g}$ School of Biosciences, The University of Nottingham, Sutton Bonington Campus, Sutton Bonington, Leicestershire LE12 5RD, United Kingdom
}

Chris Marshalla, b, *, David J. Large ${ }^{\mathrm{b}}$, Ahmed Athab ${ }^{\mathrm{c}, ~ a}$, Stephanie L. Evers ${ }^{\mathrm{d}, \mathrm{e}, \mathrm{f}}$, Andrew Sowter ${ }^{\mathrm{c}}$, Stuart Marsh ${ }^{\mathrm{a}}$,

\section{A R T I C L E I N F O}

\section{Keywords:}

InSAR

Intermittent SBAS (ISBAS)

Subsidence

Kuala Lumpur Airport

Tropical peat

Settlement

\begin{abstract}
A B S T R A C T
Rapid population growth in South-East Asia has placed immense pressure upon lowland regions both to supply food and employment and space for residential, commercial and infrastructure development. This pressure has led to sites on tropical peatland previously considered unsuitable for development to be revisited. One such site, the KLIA2 terminal and runway, Kuala Lumpur International Airport which opened in May 2014 at a cost of 3.6 billion MYR has been beset by well documented subsidence problems. Coverage of the tropics by the Sentinel-1 satellite constellation presents an opportunity to monitor the ongoing subsidence at KLIA 2, identify potential knowledge gaps and help inform more sustainable infrastructure development in tropical peatland regions. Our results show that the ISBAS InSAR method produces reproducible ground deformation maps which can clearly identify the patterns of deformation across both urban infrastructure and adjacent rural plantations and tropical peat swamp. This is particularly well defined around the terminal building at KLIA-2 where different ground preparation and foundation design have resulted in stable terminal buildings and subsidence of surrounding pavement. Deformation is greatest in the runway area where alternate bands of uplift and subsidence presumably accompany the greatest loads associated with landing aircraft. In contrast, areas where peat replacement was the primary form of ground preparation, ground motion is stable, however this comes at high economic and environmental cost.
\end{abstract}

\section{Introduction}

Shortage of suitable land for construction of key infrastructure such as roads and airports has meant that avoidance of tropical peatland and organic rich soils for development is in many cases considered unrealistic. Kuala Lumpur International Airport, Peninsular Malaysia, opened in 1997 and overlies the Kuala Langat South Peatland (Fig. 1). During construction, an excavation and replacement approach was used to mitigate against peat consolidation. The technique was effective but was expensive, increased construction time (Yap, 2015) and came at high environmental cost (emissions and damage to peatland integrity). In terms of $\mathrm{C}$ emissions, the removal of a conservative esti- mate of $7.5 \mathrm{~km}^{3}$ of peat with a density $100 \mathrm{~kg} / \mathrm{m}^{3}$ and SOC of $50 \%$ (Matysek et al., 2017), would release a minimum of $1376 \mathrm{kt}$ of $\mathrm{CO}_{2}$ equivalent to the atmosphere, $1.21 \%$ of total Malaysian emissions in 1998 when KLIA was first built (World Bank, 2017). Clearly if this approach was favoured across SE Asia, representing 11-14\% of the global carbon pool (Page et al., 2011) it would have dramatic climatic and environmental implications. This effectively limits the use of this approach in most interventions on tropical peat and means other techniques must be utilised.

Expansion of the airport in 2014 at a cost of 3.6 billion MYR utilised vacuum preloading and vertical drainage alongside surface reinforcement measures in an effort to reduce construction time and cost (Yap, 2015). These techniques are well established in the construction

\footnotetext{
* Corresponding author at: Nottingham Geospatial Institute, The University of Nottingham, Triumph Rd, Nottingham NG7 2TU, United Kingdom.

Email address: christopher.marshall@nottingham.ac.uk (C. Marshall)
} 


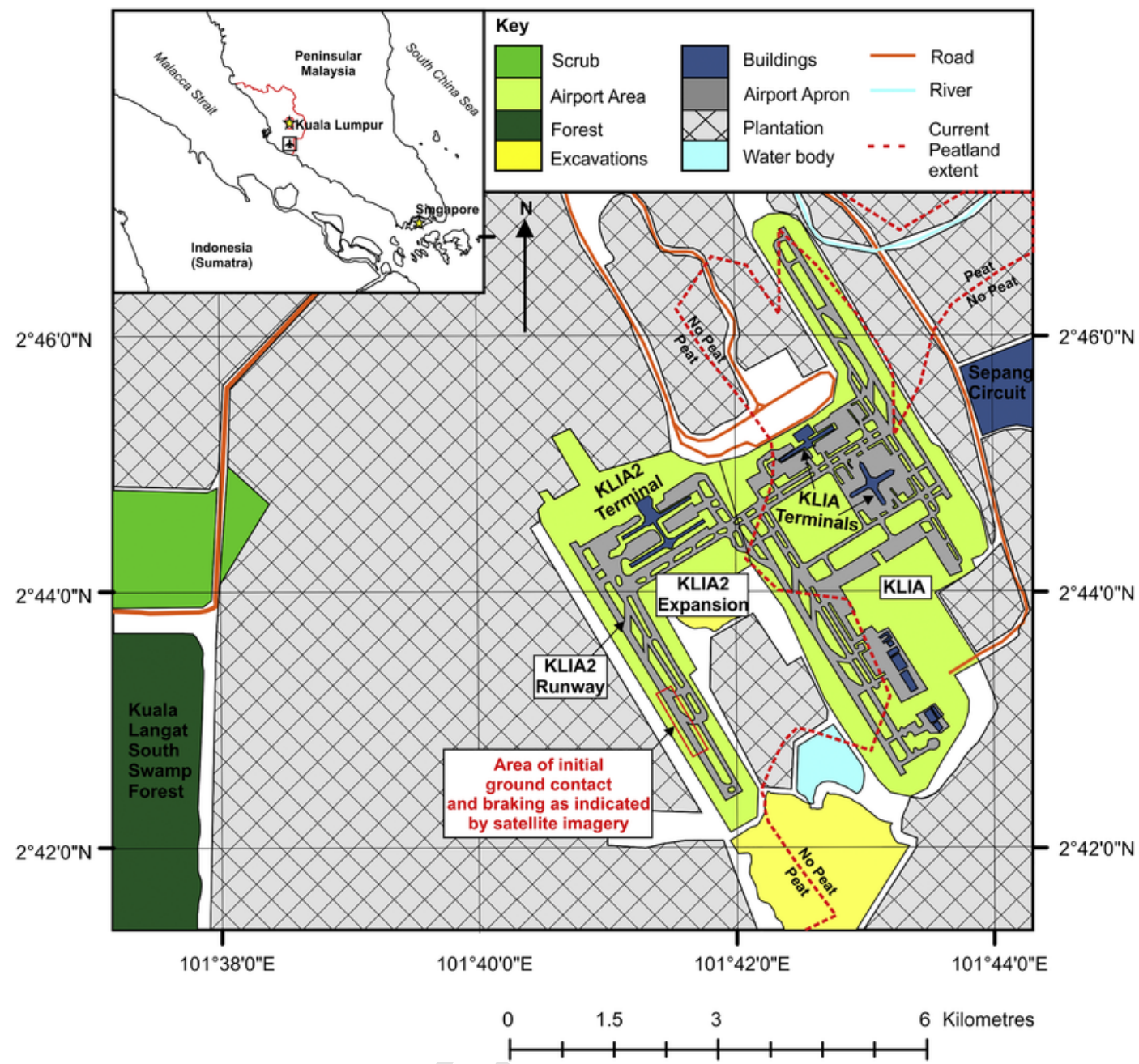

Fig. 1. Overview map of Kuala Lumpur International Airport (KLIA) including an outline of land use on peat soils in the area (Global Forest Watch, 2017).

of roads and highways in temperate regions (Carlsten, 1988; Carlsten, 2000; Samson and Rochelle, 1972). However, consolidation predictions from the use of the technique are notoriously difficult, requiring extensive pre-planning, monitoring and adaptation to onsite ground conditions. Within a year of operations settlement problems resulted in fractured fuel pipes, runway and apron ponding and alleged aircraft damage and legal action (Holmes, 2015; Morris, 2015; Yap, 2015). Consolidation rates were quoted in the range $20 \mathrm{~mm} / \mathrm{month}$ (Air Asia) to 2.9-12.9 mm/month (MAHB; (Yap, 2015) with parts of the runway having subsided by at least $50-100 \mathrm{~mm}$ since opening. Resurfacing costs have been estimated at between 50 and 100 MYR/yr (Yap, 2015).

ISBAS InSAR provides an independent method of validation and monitoring of the deformation within the airport area allowing these broad estimates to be examined. In addition, the technique allows for the first time, the impact of large scale development of tropical peatland sites on adjacent rural (low coherence sites) to be observed.

\subsection{Construction on peat}

Peat is defined within a UK context as a soil with a surface organic layer $>0.5 \mathrm{~m}$ deep and an organic matter content in excess of $60 \%$ and a deep peat as a peat soil in excess of $1.0 \mathrm{~m}$ deep (JNCC, 2011). This classification varies significantly globally, however for consistency purposes the above definitions are applied throughout this paper. In an engineering context peats can be classified by the Von Post humification scheme (Von Post, 1922) ranging from $\mathrm{H}_{1}$ (No decomposition, easily identifiable plant structure) to $\mathrm{H}_{10}$ (complete decomposition, no discernible plant structure), moisture content and principle plant components (fibrous, amorphous granular and woody; (Hobbs, 1986).

Peat as a building substrate in the northern high latitudes (Nordic Countries, Scotland) is well established and as such numerous techniques have been developed to mitigate settlement problems associated with loading (Carlsten, 1988, 2000; FCE and SNH, 2010; MacCulloch, 2006; Munro, 2005; Munro and MacCulloch, 2006; Samson and Rochelle, 1972). These problems arise from the consolidation and settlement of peat on application of load and have been extremely difficult to predict and quantify due to inherent heterogeneities both within and between different peat deposits. As a result, the consolidation process has been defined empirically in a simplified form comprising two stages; primary and secondary consolidation.

Primary consolidation occurs during initial loading and often represents the phase of greatest peat settlement. This primary phase is associated with expulsion of free water into adjacent peat in response to load causing localised pore pressure increases (Carlsten, 1989). If loading is not introduced slowly enough catastrophic failure in the form of bog bursts and slides can be triggered (Dykes and Warburton, 2007; MacCulloch, 2006; Warburton et al., 2004). This is followed by a more sustained period of subsidence, which although at reduced rate can persist for as much as 30 years post initial loading (Munro, 2005; Radforth, 1969) This second phase is commonly attributed to the reorganisation of organic fragments into a higher density, lower permeability matrix. 
The degree of deformation during the primary consolidation phase can be estimated using the Carlsten method (Carlsten, 1989). It relies upon an empirical relationship between known water content, peat thickness and load observed in Swedish high latitude peats to predict the time and extent of primary consolidation. Secondary consolidation can occur after or concurrently with primary consolidation. In many peats, secondary consolidation follows an apparently logarithmic relationship with the rate of consolidation decreasing over time (Mesri and Ajlouni, 2007; Mesri et al., 1997).

In order to mitigate against excessive settlement associated with the loading of peat a number of techniques have been developed with the relative costs and benefits of each technique discussed in detail within a temperate (Munro, 2005) and tropical (Huat et al., 2014) context. These techniques can broadly be grouped into the following categories (after Munro, 2005):

- Avoidance - Relocation of planned development away from peatland areas

- Removal and Replacement - Removal of peat and replacement with less compressible substrate.

- Preloading and surcharging - Use of load in excess of that expected in construction to increase settlement rate and to improve bearing capacity of peat.

- Rafting and geotextiles - Support and distribute load at peat-construction interface reducing chance of differential compaction.

- Piling - transmits load to a higher strength substrate e.g. Bedrock, subsoil.

- Mass Stabilisation - Mixing of the soil with a binding agent to improve material strength.

In practice, a combination of these ground treatment works is often applied according to the conditions on site. Many of these techniques, (developed in high latitude peatlands) have been applied in tropical settings (Huat et al., 2014). However, tropical peat is structurally different from high latitude peats with differing fibre contents (Huat et al., 2014) and permeability (Baird et al., 2017). In addition with soil temperatures ranging between 22.9 and $30.2^{\circ} \mathrm{C}$ (Jaya, 2007), heterotrophic respiration is greatly enhanced (Jauhiainen et al., 2014). This may mean that the direct application of techniques developed for use at high latitude without adaptation may not be suitable for use in the tropics. This is compounded by a paucity of studies specifically related to the influence of decay and hydrology on the loading of tropical peat.

\subsection{InSAR measurement of peat surface deformation}

Interferometric Synthetic Aperture Radar (InSAR) measurements from satellite constellations such as Sentinel-1 offer the opportunity to measure settlement covering an area and sampling frequency (Max. 6 day repeat) which would be impractical to achieve through ground and LiDAR techniques (Milillo et al., 2016). InSAR has been applied to monitor deformation over large infrastructure projects such as Hong Kong Airport (Jiang and Lin, 2010) and peat related subsidence in urban areas (Peduto et al., 2017;).

Despite some efforts to extend the coverage of time-series InSAR surveys to give better coverage in outside of urban and rocky areas (e.g. Hooper, 2008; Ferretti et al., 2011), the majority of InSAR time-series techniques either fail to work or provide very sparse coverage in the presence of vegetation (Crosetto et al., 2010; Osmanoglu et al., 2015). The recent development of the Intermittent Small Baseline Subset (ISBAS) DInSAR algorithm (Bateson et al., 2015; Gee, 2016; Gee et al., 2016; Gee et al., 2017; Sowter et al., 2013; Sowter et al., 2016) extends further the ability to measure subsidence over vegetated, low co- herence areas. Indeed, improvements in coverage from between 4 and 26 times that of conventional DInSAR time-series methods have been observed over such areas with the ISBAS technique (Cigna and Sowter, 2018).

Recent InSAR studies using ISBAS (Cigna and Sowter, 2018; Sowter et al., 2018; Alshammari et al., 2018) and persistent scatterer interferometry (PS InSAR; Cuenca and Hanssen, 2008) have been used to monitor peatland deformation. Morishita and Hanssen (2015) also examined coherence behaviour over peatland using PS InSAR and SBAS. . ISBAS InSAR covers high coherence areas such as buildings and infrastructure, in addition to monitoring the effects of construction on ground motion in low coherence areas outside the immediate vicinity of development. This is of particular use in peatland where hydrological connectivity may be high and disruption of flow may lead to unexpected problems in rural areas previously missing from InSAR analysis.

Although L-band radar data is more suited to the large range of motions expected within tropical peatlands (Wösten et al., 1997; Hooijer et al., 2012), L band data is often not available in sufficient quantities within the same relative orbits required for InSAR over tropical peatland areas. For example the current ALOS-2 satellite has fewer than five radar measurements over the period 2014-2018 in the South Selangor study area. Sentinel 1 however (C band) has in excess of 80 measurements over the same period with average return times of approximately 12 days. If this can be used even qualitatively, this has the potential to fill a conspicuous gap in global ground motion monitoring provision.

\subsection{Objectives}

In this study, we apply the ISBAS method (Sowter et al., 2013) to Sentinel-1 DInSAR observations from an ascending 70 track (Oct 2014-June-2017) and the descending 91 track (Oct 2014-Oct 2017) over an area incorporating Kuala Lumpur International Airport, Selangor (Peninsular Malaysia) and compare with previously recorded quantitative and qualitative measures of ground motion. This study has several objectives: to determine whether the direction and scale of ground motion estimates reported by Yap, 2015 is replicated by InSAR measurements and to determine which of the broad range of values are most appropriate. In addition, this study will determine whether differing ground preparation measures can be distinguished using InSAR measurements and examine the wider effects of infrastructure development on adjacent peatlands and use this to identify any potential knowledge gaps in tropical peatland construction.

\section{Data coverage and method}

\subsection{Study area}

The study focuses on the area of Kuala Lumpur International Airport, Selangor, Peninsular Malaysia (Fig. 1). The area overlies formerly extensive peatlands with a small area of remnant primary forest preserved at the adjacent Kuala Langat South Forest Reserve. Encroachment and conversion of peatland to oil palm usage since the 1970's has reduced the size of the forested reserve significantly, however peat still underlies many areas of oil palm plantation. Remaining peat is estimated to range in thicknesses from between $<0.1$ and $2.1 \mathrm{~m}$ (Matysek et al., 2017). Deforested areas are prone to fire and illegal encroachment/farming practises pose a significant risk to the survival of the remaining forest reserve. However, a new risk to the whole of the south Selangor peat area is urbanisation for housing and key infrastructure as the suburbs of Kuala Lumpur expand to cope with rapid population growth. 


\subsection{Sentinel-1 ISBAS processing}

The study area was covered by 76 sentinel-1A interferometric wide swath single look complex Level 1 images acquired in ascending orbit (relative orbit 70) over 960 days incorporating the period 22 October 2014 to 8th June 2017 (Copernicus, 2017) with acquisitions repeated every 12-24 days and by 66 images acquired in descending orbit (relative orbit 91) incorporating the period 23 October 2014 to 7th October 2017 , a period of 1080 days (Table 1 ).

Images were processed using the modified ISBAS processing chain for Sentinel-1 outlined by Sowter et al. (2013) and Sowter et al. (2016) to assess peat surface deformation in the two study areas. Briefly, after co-registration (slave images co-registered to master coordinate system), differential interferograms over a short orbital baseline were created. Maximum horizontal baseline was restricted to $250 \mathrm{~m}$ with maximum temporal separation of 1 year. This incorporated half the period of observation covered by the 76 and 66 images respectively from the study area. ISBAS processing generated 1334 and 492 multi-looked differential interferograms over the study area for the ascending and descending orbits respectively. All images were multi-looked by a factor of 22 and 5 pixels in range and azimuth directions to produce pixel dimensions of about $80 \times 70 \mathrm{~m}$ ground resolution.

Coherent pixels were identified by applying a coherence threshold of 0.25 to the interferograms and a point threshold of 370 . The threshold produced coverage over the study area of $94.35 \%$ of possible pixels. Had velocities been derived for targets where coherence is recurrent in every interferogram, coverage would have been only $25.35 \%$. Spatial coverage is gained at the expense of ISBAS result quality and therefore the threshold chosen attempts to optimise coverage against quality (Sowter et al., 2013). The relationship between quality and coverage has been empirically defined by Cigna and Sowter (2018) and indicates that on average the relationship between standard error and number of interferograms can be defined as $\varepsilon_{\mathrm{vel}}=11 / \sqrt{ } \mathrm{n}_{\mathrm{i}}$ where $\varepsilon_{\mathrm{vel}}$ is the desired standard error and $n_{i}$ is the number of interferograms used. Cigna and Sowter (2018) show that by assuming a maximum vertical standard error of $1 \mathrm{~mm} / \mathrm{yr}$, at least 121 interferograms are required to achieve desired precision. Achieving this threshold is greatly aided by the high return frequency available from Sentinel 1a/1b.

Phase unwrapping was implemented using the SNAPHU method (Chen and Zebker, 2001) to individually unwrap all the ISBAS points within each interferogram. Post-unwrapping line of sight (LOS) linear velocities and standard deviation of coherent points were derived relative to a stable reference point located at KLIA Airport (South Selangor, $101.713928 \mathrm{~N} 2.748086 \mathrm{E}$ ). Deformation results are relative to these points; therefore, reference points are required to be stable. In the absence of accurate ground data, the choice of reference point was made by considering the coherence of the signal and minimum standard error in the phase in all interferograms (points with minimum standard error and high coherence). Linear velocity values (LOS) were then converted into more useful vertical velocity $\left(\mathrm{v}_{\mathrm{vert}}\right)$ values $\left(\mathrm{v}_{\mathrm{vert}}=\mathrm{v}_{\mathrm{LOS}} / \cos \Theta\right.$ where $\Theta=$ incidence angle). This assumes that there is only vertical deformation over the study area, which at the pixel scale, field validation indicates is plausible.

\section{Results}

\subsection{Quality of InSAR result}

The use of both ascending and descending runs over the study area allows the reproducibility of the ISBAS InSAR result to be verified. As both stacks cover approximately similar periods but are derived from independent orbits the difference between the datasets allows the consistency/precision of the processing result to be determined.
Comparison of the ISBAS results (Fig. 2E) over KLIA airport shows that the difference between the results from ascending and descending relative orbits is on average $1.1 \mathrm{~mm} / \mathrm{yr} \pm 3.1 \mathrm{~mm} / \mathrm{yr}$ and for the entire study area, $2.7 \mathrm{~mm} / \mathrm{yr} \pm 3.1 \mathrm{~mm} / \mathrm{yr}$. In the context of typical annual rates of motion measured on peatland of between 20 and $100 \mathrm{~mm}$ (Wösten et al., 1997; Hooijer et al., 2012), the agreement between the two datasets is good and within the natural variation measured by ground techniques. Additionally when compared with the widely reported rates of $35 \mathrm{~mm} / \mathrm{yr}$ and $240 \mathrm{~mm} / \mathrm{yr}$ (Yap, 2015), the agreement is much greater than is currently available from alternative techniques. The difference between the two datasets is not constant over the study area (Fig. 2E). Agreement is greatest within areas of low motion and lowest within areas of rapid motion. The descending pass (Fig. 2C) is visibly noisier than the ascending pass (Fig. 2A). The descending dataset also shows elevated standard error over rural areas. This difference in quality is in part due to the lower number of interferograms generated in the descending pass over the area of interest (2017). The small differences between the two datasets (Fig. 2E) in addition to noise may also reflect minor horizontal displacement over the study site. However, since these are small, it confirms the assumption that motion over the site is predominantly vertical. The ascending dataset is as a consequence considered more likely to accurately reflect the true rate of surface motion.

Examination of the standard error (Fig. 2B, D) shows a similar distribution for both ascending and descending orbits with lowest error over highly coherent sites such as the airport $(<1 \mathrm{~mm} / \mathrm{yr})$ and increased but consistent error over more rural sites $(3-4 \mathrm{~mm} / \mathrm{yr})$. This is a consequence of the more intermittent coherence over these areas reducing the number of interferograms utilised within each pixel measurement described by Cigna and Sowter (2018). Nevertheless the precision achieved by the ISBAS InSAR technique at least matches or even exceeds that of currently employed ground techniques in tropical peatlands (Hooijer et al., 2012). The ISBAS InSAR technique and C-band radar has proven to be a precise method of measuring motion over tropical peatland and it is therefore considered appropriate to examine its use in interpreting the ground motion over KLIA.

\subsection{Patterns of deformation}

At large-scale both ascending and descending InSAR measurements over KLIA (constructed 1997) show little or no ground motion (Fig. $2 \mathrm{~A}, \mathrm{C}$ ) whilst the later airport extension (KLIA 2) shows a clear trend of deformation and subsidence. Similarly, the KLIA and KLIA2 terminal buildings show little evidence of ground movement (Fig. 2A, C). Stability of the KLIA2 Terminal Building is clearly demarcated from the subsidence in the surrounding apron, taxiways and runway. Much of the apron appears to be subject to similar rates of subsidence. Consolidation over the runway area is more complex with a repeat pattern of subsidence and uplift diminishing north-westward. Deformation closely corresponds to the position of increased loading associated with landing and braking of aircraft as marked in Fig. 1.

Interestingly the ISBAS InSAR method also shows good coverage over adjacent rural plantations (Fig. 2A, C), areas often without sufficient coherence to produce data from conventional InSAR methods. This gives the opportunity to examine deformation within a more regional context. This shows that the subsidence is widespread in the area to the west of the Airport. Land use in this area is mostly longstanding oil palm plantations (Fig. 1) in place since the early 2000's (Matysek et al., 2017). Oil palm plantations in the area show a uniform subsidence trend which compares well with published ground motion studies elsewhere in SE Asia. (Hooijer et al., 2012). An exception to this is to the north of the area where site visits have shown the total loss of peat soils exposing underlying marine clays over the past decade which are stable on the InSAR image (Fig. 2A, C). A band approx. 
Table. 1

Date of Sentinel-1 acquisition for both ascending and descending ISBAS InSAR analysis used within this study with time between images indicated.

\begin{tabular}{|c|c|c|c|c|}
\hline \multirow[t]{2}{*}{ Image no. } & \multicolumn{2}{|c|}{ Relative Orbit 70 Ascending } & \multicolumn{2}{|c|}{ Relative Orbit 91 descending } \\
\hline & Date of acquisition & Time between acquisitions & Date of acquisition & Time between acquisitions \\
\hline 1 & $10 / 22 / 2014$ & - & $10 / 23 / 2014$ & - \\
\hline 2 & $11 / 3 / 2014$ & 12 & $11 / 16 / 2014$ & 24 \\
\hline 3 & $11 / 15 / 2014$ & 12 & $11 / 28 / 2014$ & 12 \\
\hline 4 & $12 / 9 / 2014$ & 24 & $12 / 10 / 2014$ & 12 \\
\hline 5 & $1 / 2 / 2015$ & 24 & $12 / 22 / 2014$ & 12 \\
\hline 6 & $1 / 14 / 2015$ & 12 & $1 / 3 / 2015$ & 12 \\
\hline 7 & $1 / 26 / 2015$ & 12 & $1 / 15 / 2015$ & 12 \\
\hline 8 & $2 / 7 / 2015$ & 12 & $1 / 27 / 2015$ & 12 \\
\hline 9 & $2 / 19 / 2015$ & 12 & $3 / 4 / 2015$ & 36 \\
\hline 10 & $3 / 3 / 2015$ & 12 & $3 / 16 / 2015$ & 12 \\
\hline 11 & $3 / 15 / 2015$ & 12 & $3 / 28 / 2015$ & 12 \\
\hline 12 & $3 / 27 / 2015$ & 12 & $4 / 9 / 2015$ & 12 \\
\hline 13 & $4 / 8 / 2015$ & 12 & $5 / 15 / 2015$ & 36 \\
\hline 14 & $4 / 20 / 2015$ & 12 & $6 / 8 / 2015$ & 24 \\
\hline 15 & $5 / 2 / 2015$ & 12 & $7 / 14 / 2015$ & 36 \\
\hline 16 & $5 / 14 / 2015$ & 12 & $7 / 26 / 2015$ & 12 \\
\hline 17 & $5 / 26 / 2015$ & 12 & $10 / 6 / 2015$ & 72 \\
\hline 18 & 6/7/2015 & 12 & $10 / 18 / 2015$ & 12 \\
\hline 19 & $6 / 19 / 2015$ & 12 & $11 / 11 / 2015$ & 24 \\
\hline 20 & 7/1/2015 & 12 & $11 / 23 / 2015$ & 12 \\
\hline 21 & 7/13/2015 & 12 & $12 / 17 / 2015$ & 24 \\
\hline 22 & $7 / 25 / 2015$ & 12 & $12 / 29 / 2015$ & 12 \\
\hline 23 & $8 / 18 / 2015$ & 24 & $1 / 10 / 2016$ & 12 \\
\hline 24 & $8 / 30 / 2015$ & 12 & $2 / 3 / 2016$ & 24 \\
\hline 25 & $9 / 11 / 2015$ & 12 & $2 / 15 / 2016$ & 12 \\
\hline 26 & $10 / 5 / 2015$ & 24 & $3 / 10 / 2016$ & 24 \\
\hline 27 & $10 / 17 / 2015$ & 12 & $4 / 3 / 2016$ & 24 \\
\hline 28 & $10 / 29 / 2015$ & 12 & $4 / 15 / 2016$ & 12 \\
\hline 29 & $11 / 10 / 2015$ & 12 & $4 / 27 / 2016$ & 12 \\
\hline 30 & $11 / 22 / 2015$ & 12 & $5 / 9 / 2016$ & 12 \\
\hline 31 & $12 / 4 / 2015$ & 12 & $5 / 21 / 2016$ & 12 \\
\hline 32 & $12 / 16 / 2015$ & 12 & $6 / 2 / 2016$ & 12 \\
\hline 33 & $12 / 28 / 2015$ & 12 & $6 / 14 / 2016$ & 12 \\
\hline 34 & $1 / 9 / 2016$ & 12 & $7 / 8 / 2016$ & 24 \\
\hline 35 & $1 / 21 / 2016$ & 12 & $7 / 20 / 2016$ & 12 \\
\hline 36 & $2 / 2 / 2016$ & 12 & $8 / 1 / 2016$ & 12 \\
\hline 37 & $2 / 14 / 2016$ & 12 & $8 / 13 / 2016$ & 12 \\
\hline 38 & $2 / 26 / 2016$ & 12 & $8 / 25 / 2016$ & 12 \\
\hline 39 & $3 / 9 / 2016$ & 12 & $9 / 6 / 2016$ & 12 \\
\hline 40 & $3 / 21 / 2016$ & 12 & $9 / 18 / 2016$ & 12 \\
\hline 41 & $4 / 2 / 2016$ & 12 & $9 / 30 / 2016$ & 12 \\
\hline 42 & $4 / 14 / 2016$ & 12 & $10 / 12 / 2016$ & 12 \\
\hline 43 & $4 / 26 / 2016$ & 12 & $10 / 24 / 2016$ & 12 \\
\hline 44 & $5 / 8 / 2016$ & 12 & $11 / 17 / 2016$ & 24 \\
\hline 45 & $5 / 20 / 2016$ & 12 & $12 / 11 / 2016$ & 24 \\
\hline 46 & $6 / 1 / 2016$ & 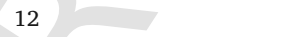 & $1 / 4 / 2017$ & 24 \\
\hline 47 & $6 / 13 / 2016$ & 12 & $1 / 16 / 2017$ & 12 \\
\hline 48 & 7/7/2016 & 24 & $1 / 28 / 2017$ & 12 \\
\hline 49 & 7/19/2016 & 12 & $2 / 21 / 2017$ & 24 \\
\hline 50 & $7 / 31 / 2016$ & 12 & $3 / 5 / 2017$ & 12 \\
\hline 51 & $8 / 12 / 2016$ & 12 & $3 / 17 / 2017$ & 12 \\
\hline 52 & $8 / 24 / 2016$ & 12 & $3 / 29 / 2017$ & 12 \\
\hline 53 & $9 / 5 / 2016$ & 12 & $4 / 10 / 2017$ & 12 \\
\hline 54 & $9 / 17 / 2016$ & 12 & $4 / 22 / 2017$ & 12 \\
\hline 55 & 9/29/2016 & 12 & $5 / 4 / 2017$ & 12 \\
\hline 56 & $10 / 11 / 2016$ & 12 & $5 / 16 / 2017$ & 12 \\
\hline 57 & $10 / 23 / 2016$ & 12 & $5 / 28 / 2017$ & 12 \\
\hline 58 & $11 / 4 / 2016$ & 12 & $6 / 9 / 2017$ & 12 \\
\hline 59 & $11 / 16 / 2016$ & 12 & $6 / 21 / 2017$ & 12 \\
\hline 60 & $11 / 28 / 2016$ & 12 & $7 / 3 / 2017$ & 12 \\
\hline 61 & $12 / 10 / 2016$ & 12 & $7 / 15 / 2017$ & 12 \\
\hline 62 & $12 / 22 / 2016$ & 12 & 8/8/2017 & 24 \\
\hline 63 & $1 / 3 / 2017$ & 12 & $9 / 1 / 2017$ & 24 \\
\hline 64 & $1 / 15 / 2017$ & 12 & $9 / 13 / 2017$ & 12 \\
\hline 65 & $1 / 27 / 2017$ & 12 & $9 / 25 / 2017$ & 12 \\
\hline 66 & $2 / 8 / 2017$ & 12 & $10 / 7 / 2017$ & 12 \\
\hline 67 & $2 / 20 / 2017$ & 12 & & \\
\hline 68 & $3 / 4 / 2017$ & 12 & & \\
\hline 69 & $3 / 16 / 2017$ & 12 & & \\
\hline 70 & $3 / 28 / 2017$ & 12 & & \\
\hline 71 & 4/9/2017 & 12 & & \\
\hline 72 & $4 / 21 / 2017$ & 12 & & \\
\hline
\end{tabular}


Table. 1 (Continued)

\begin{tabular}{|c|c|c|c|c|}
\hline \multirow[t]{2}{*}{ Image no. } & \multicolumn{2}{|c|}{ Relative Orbit 70 Ascending } & \multicolumn{2}{|c|}{ Relative Orbit 91 descending } \\
\hline & Date of acquisition & Time between acquisitions & Date of acquisition & Time between acquisitions \\
\hline 73 & $5 / 3 / 2017$ & 12 & & \\
\hline 74 & $5 / 15 / 2017$ & 12 & & \\
\hline 75 & $5 / 27 / 2017$ & 12 & & \\
\hline 76 & 6/8/2017 & 12 & & \\
\hline
\end{tabular}

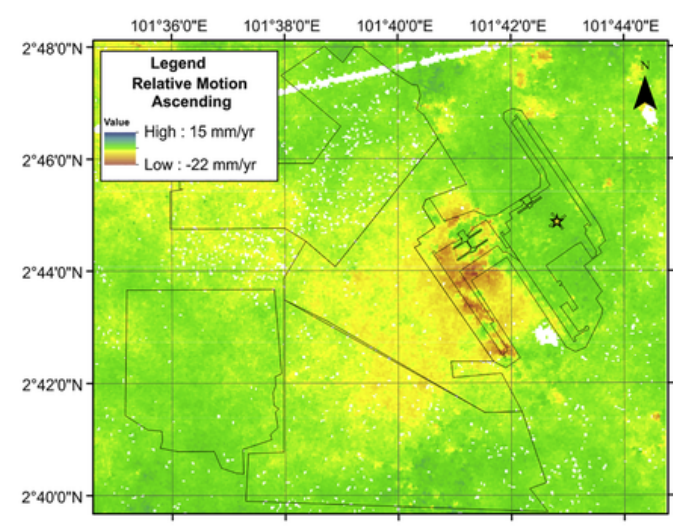

A

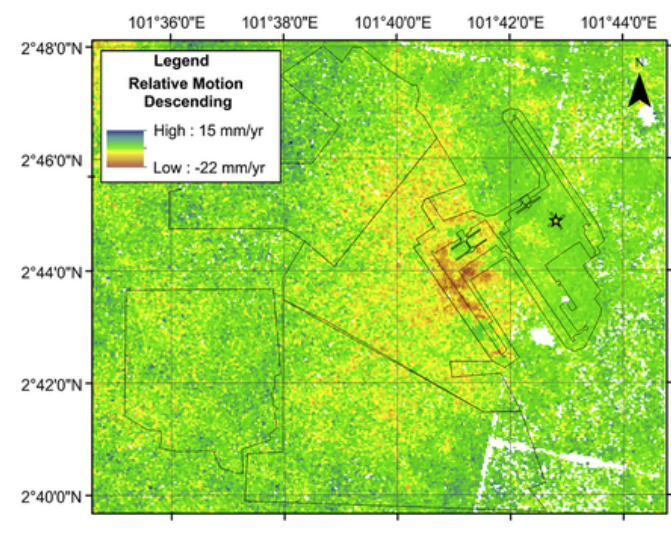

c $\stackrel{0}{1}, 1.5,3,3,6$ Kilometres

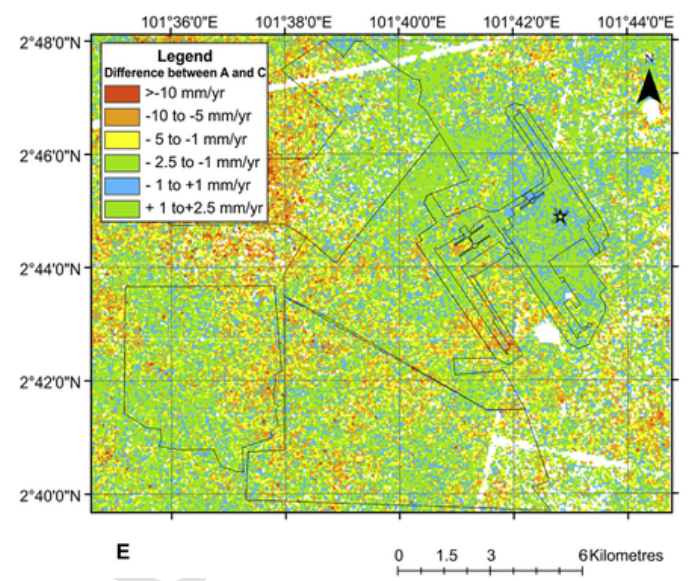

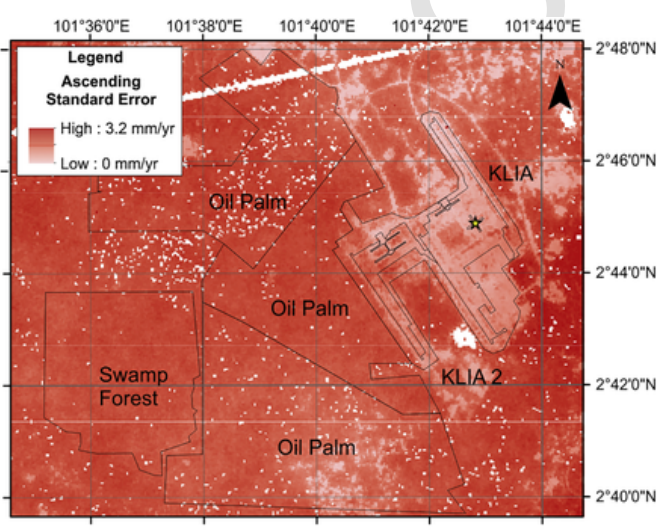

B
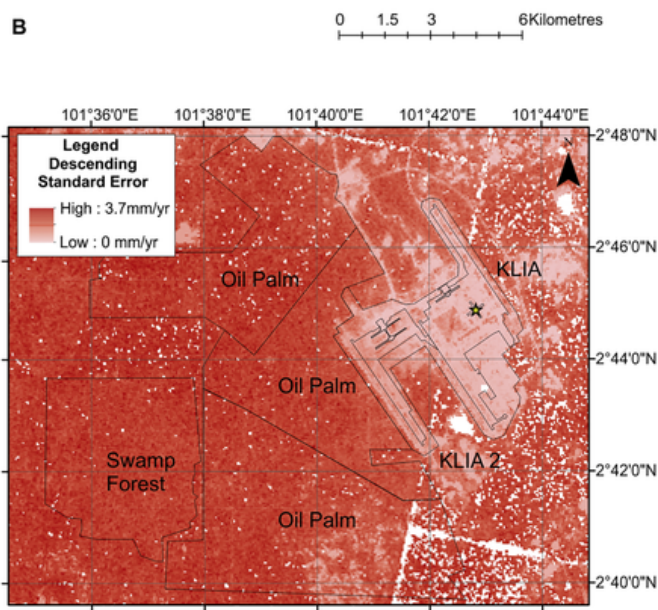

D

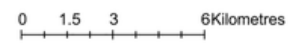

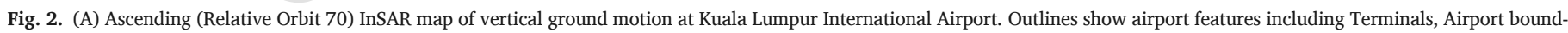

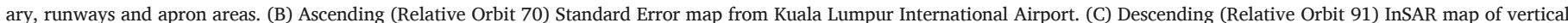

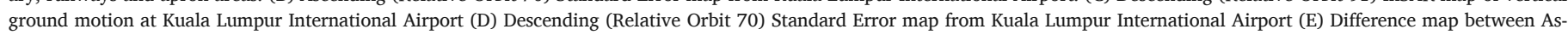
cending and Descending tracks for the three years studied. Star shows position of reference point from which all motion is relative. 
$500 \mathrm{~m}$ wide fringing the airport shows elevated peat surface subsidence compared to elsewhere within the oil palm plantations.

\subsection{Quantification of deformation}

Validation of the rates of deformation at Kuala Lumpur International Airport is difficult. High quality GNSS data is not currently available over the study site. This is a common problem with collection of concurrent reliable ground data within the area of interest very rare. Where this has occurred in temperate regions, the accuracy of rates in temperate regions has been within $1.12-1.52 \mathrm{~mm}$ /year (Gee et al., 2016). Lower quality ground motion information is available for the site. However as previously stated, rate estimates differ significantly between sources ( $35 \mathrm{~mm} / \mathrm{yr}$ and $240 \mathrm{~mm} / \mathrm{yr}$; Yap, 2015). ISBAS InSAR has proven accurate over other low latitude sites $(<1.2 \mathrm{~cm} /$ year difference) over highly coherent urban sites similar to KLIA (Sowter et al., 2016) with a much reduced stack of images (18 vs. 76 ). The application of this technique over the KLIA study area may therefore provide supporting evidence for which of the estimates is most appropriate. As the ascending dataset appear to contain the least noise and lowest standard errors, only these values are considered in the following section.

Mean rates of ground motion across the Kuala Lumpur International Airport site measured using the ISBAS technique are around $-2.4 \mathrm{~mm} / \mathrm{yr} \pm 1.4 \mathrm{~mm} / \mathrm{yr}$. Similar rates of relative ground motion are observed within the piled KLIA terminal buildings $(<1 \mathrm{~mm} / \mathrm{yr})$ KLIA terminals with KLIA 2 slightly higher due to pixels containing both piled airport terminal buildings and adjacent pavement. These rates are reasonable in that there are no reported subsidence problems at the 1998 KLIA airport and terminal buildings (Yap, 2015). In the apron areas of KLIA 2 InSAR measured mean rates of settlement are in the range $10.5 \mathrm{~mm} / \mathrm{yr} \pm 4.4 \mathrm{~mm} / \mathrm{yr}$. However a substantial proportion of the runway area contains values in excess of $-20 \mathrm{~mm} / \mathrm{yr}$. This more than five times greater the maximum values measured at KLIA and when non-paved areas are removed, $>10$ times that of the pavement at KLIA $(1-2 \mathrm{~mm} / \mathrm{yr})$.

As described in the previous section, deformation is more complex in the runway area. Much of the runway has similar rate of settlement to the apron areas at $13 \mathrm{~mm} / \mathrm{yr} \pm 3.7 \mathrm{~mm} / \mathrm{yr}$. However at the southernmost part of the runway bands of stable/slight uplift ground motion (max. $+0.37 \mathrm{~mm} / \mathrm{yr}$ ) run perpendicular to the runway. This alternating high subsidence-uplift/stable-high subsidence trend decreases toward northward toward the terminal. Greatest uplift (Fig. 2A, C) is offset from the point of landing indicated by the position of tyre marks (Fig. 1). This may be caused by a rippling of the runway surface in response to the additional loading upon aircraft landing and braking.

Despite matching ground observations qualitatively, in that areas of stable and subsiding land are identifiable and are where expected, mean rates derived from InSAR are lower than the range of values frequently cited on the ground ( $35 \mathrm{~mm} / \mathrm{yr}$ and $240 \mathrm{~mm} / \mathrm{yr}$; Yap, 2015). The InSAR data indicates it is very unlikely that the highest estimates are correct as if the rate of motion was constant this would equate to a constant rate of $8 \mathrm{~mm} / 12$ days pair which is easily measurable by C-band InSAR (Crosetto et al., 2016; Motagh et al., 2017). The difference between upper ISBAS InSAR and lowest ground estimate is in the order of $1.4 \mathrm{~cm} /$ year similar to that observed in Mexico City (Sowter et al., 2016). The evidence from ISBAS InSAR appears to indicate the lower estimates of subsidence at the airport may be most appropriate over the long-term.

Mean subsidence in the oil palm plantations is between $5 \mathrm{~mm}$ / $\mathrm{yr} \pm 2.5 \mathrm{~mm} / \mathrm{yr}$ to $7.6 \mathrm{~mm} / \mathrm{yr} \pm 1.3 \mathrm{~mm} / \mathrm{yr}$. Subsidence in fringe areas is augmented with maximum values in the order of $11 \mathrm{~mm} / \mathrm{yr}$. Natural remnants of swamp forest at Kuala Langat South show values of $4 \mathrm{~mm} /$ $\mathrm{yr} \pm 1.3 \mathrm{~mm} / \mathrm{yr}$ with highest values in areas immediately adjacent to areas of oil palm conversion and drainage. Areas away from the forest edge show more stability with values of peat surface motion in the order of $-1-2 \mathrm{~mm} / \mathrm{yr}$. Expected rates of peat surface subsidence in converted drained oil plantations on peat land are approximately $-50 \mathrm{~mm} /$ yr (Hooijer et al., 2012). Even 20 years after initial drainage rates of $-20 \mathrm{~mm} / \mathrm{yr}$ (Wösten et al., 1997) are expected. Given this, the rates from InSAR are likely under predicted, with mean annual peat surface subsidence rates in oil palm out by an approximate factor of two-three compared with expected rates 15-20 years since conversion (Wösten et al., 1997). This factor between InSAR and ground measurements may be useful for correcting InSAR data. However to quantify this with sufficient rigour requires much better ground validation data than is currently available.

\section{Discussion}

\subsection{Ability of ISBAS technique to quantify ground deformation over tropical peatlands}

Before describing the application of the InSAR tool to the monitoring of tropical peat construction techniques at Kuala Lumpur International Airport, we first reflect on the limitations of the technique and consider some ways to overcome these in the future. This will allow us to better define the current and future potential of the technology for monitoring construction on tropical peats. The biggest limitation relates to the maximum ground motion that can be measured in the absence of a well-defined fringe pattern. If phase unwrapping fails completely, as it may do in an incoherent area such as a forest, this could be as low as $1.4 \mathrm{~cm}$ between image pairs, as determined by the wavelength of the radar at $5.6 \mathrm{~cm}$. In temperate, northern latitudes, this is not a problem because rates of motion over peat are low, but in these tropical settings rates can reach up to $1 \mathrm{~m}$ /year (Hooijer et al., 2012; Hooijer et al., 2015) and this greatly exceeds the capability of the sensor to make the measurement. In circumstances like this, such as at the airport site in the current study, the surface motion is consequently under-estimated. In addition, the lack of detailed ground data from this area also makes it difficult to validate InSAR ground motion. Another issue is that unlike most applications of InSAR data, the expected motion is unlikely to be uni-directional. Tropical peat surface motion is seasonal with natural range in the order of $10-20 \mathrm{~cm}$ (Hooijer et al., 2012; Hooijer et al., 2015). This dynamism is complicated further by the response of peatland surface to sudden weather events such as heavy rain, making the chance of exceeding the ambiguity threshold of $1.4 \mathrm{~cm}$ much more likely than observed during other applications.

There are several potential ways around this problem. In terms of development of the InSAR technique, the temporal baseline or time-separation of the image-pairs used can be reduced to limit the magnitude of displacement observed. In higher latitudes, a repeat cycle of 6 days is now being achieved regularly since the launch of Sentinel-1b. If this could be extended to the tropics that would make an immediate difference, meaning that $1.4 \mathrm{~cm}$ of change could be measured over 6 days rather than 12. This is a matter of power management as SAR sensors consume so much energy it is impossible to gather data constantly for every orbit without depleting power reserves; therefore, under current mission plans power is conserved for acquisitions over Europe, which are prioritised as Sentinel-1 is a European satellite. Could this be re-visited for the purposes of peat monitoring?

Reducing the temporal baseline increases the amount of motion that can be measured per year, but there are trade-offs in terms of reducing the number of interferometric pairs which increases noise limiting our ability to do this. For specific cases where motion is known to be higher than the limit, another possible approach is to supplement the use of the ISBAS technique using conventional InSAR on a pair of images that straddle the change, to resolve the higher motion rate. By gradually increasing the temporal separation of the images and exam- 
ining the developing interferometric fringes the effect of ambiguity (which is not possible within a pixel based approach) may provide an independent verification of the ISBAS measurements. This method may therefore (in large-scale high coherence areas) be of use in quantifying the ambiguity effect on the pixel based ISBAS approach. However, at $\mathrm{C}$ band it will frequently prove to be impossible to gain sufficient coherence and coverage, especially over a forested /rural target (as in the KLIA case), for this measurement to be made and unwrapped successfully.

It might also be plausible to switch wavelength, perhaps using an L-band sensor. For example, the PALSAR sensor aboard the ALOS-2 satellite had a wavelength of $23.6 \mathrm{~cm}$, as opposed to $5.6 \mathrm{~cm}$ for Sentinel-1, which would greatly increase the amount of motion that could be measured for a similar temporal baseline. Unfortunately, although $>30$ images have been collected over the study area since 2014, very few $(<5)$ have been collected within the same orbital track, making comparison with the much higher frequency $\mathrm{C}$ band data impossible. ALOS-2L-band data unlike Sentinel I data is not free to the end user, restricting it's use to many end users due to budgetary constraints The use of $\mathrm{L}$ band also raises another problem, whilst $\mathrm{L}$ band measures the high rates expected associated with peatland conversion, there is a loss of sensitivity in areas with low rates of motion. Despite these problems a future comparison of the relative merits of $\mathrm{L}$ band and Sentinel 1C-band in an area with good L-band coverage would go a long way to resolving these issues.

\subsubsection{Ability of the ISBAS technique to identify patterns of peat related settlement}

Despite difficulties in replicating vertical motion rates due to the limitations of C-band radar over fast moving deformation, ISBAS replicates the patterns of motion described at the KLIA site (Yap, 2015) well. It also appears to accurately identify areas of reported low or limited motion. Different building techniques have very different settlement characteristics with piling followed by remove and replace producing the most stable ground. Preloading and vertical drainage at the KLIA2 site appears to produce the highest settlement rates. In addition, the technique appears prone to differential compaction particularly in areas of sudden loading such as the runway. This produces more complex deformation than seen elsewhere on the site with evidence of uplift perpendicular to aircraft motion.

The ability to detect motion over vegetated tropical peatland using C-band radar is novel and replicates observations from temperate peatlands (Cigna and Sowter, 2018; Sowter et al., 2018). This allows the wider effects on ground stability of construction to be observed in real time. This is demonstrated by the fringe of increased settlement around the KLIA 2 airport extension which shows the effects of preloading and vertical drainage extending beyond the airport boundary. Whilst oil palm plantations have well documented issues regarding subsidence (Hooijer et al., 2012; Hooijer et al., 2015; Wösten et al., 1997), the InSAR image indicates that subsidence has been accelerated compared to surrounding plantations. The $500 \mathrm{~m}$ band is similar to the effect associated with large drainage canals where local peat topography has a logarithmic relationship with distance from the source of drainage (Wösten et al., 1997). This implies that peat compression may have hydrologically compromised adjacent peatland through improved drainage and increased hydrological gradient from the peat dome to the west. This would have the effect of rapidly lowering water tables and increasing peat oxidation in the immediate vicinity of the intervention. What is unknown (and requires further study) is the long-term effects that increasing hydrological gradient through loading may have at greater distance from the intervention. Potentially, hastening oxidation at the peatland fringes may result in a positive feedback loop, greatly increasing peatland instability. As such future developments considering the use of such ground preparation techniques should con- sider the offsite hydrological effects in more detail during the environmental impact stage.

\subsection{Potential knowledge gaps relating to construction on tropical peats}

\subsubsection{Oxidation and decomposition}

Consolidation is not the only factor affecting the stability of peat. Peat is primarily composed of organic carbon, preserved only under waterlogged reducing redox conditions. This oxidation effect is observed in laboratory consolidation experiments but discounted as an artefact of the laboratory environment (Mesri et al., 1997). Consequently, consolidation experiments were undertaken in abiotic conditions as this was considered more controlled and thought not dissimilar to the natural environment (Mesri and Ajlouni, 2007; Mesri et al., 1997).These assumptions were to some degree understandable within the context of high latitude peats as low temperatures and seasonality limit bacterial oxidation rates making consolidation the likely main driver of short term peat subsidence in response to loading. In addition, where preloading and surcharging is the only ground stability treatment applied, the result of compression in low hydrological conductivity high latitude blanket peatland may be expected to be at least initially highly localised. Difficulties arise when temperate peatland assumptions are applied within a tropical peatland context.

Unlike temperate peatlands, soil temperatures from tropical peats ranging between 22.9 and $30.2^{\circ} \mathrm{C}$ (Jauhiainen et al., 2014; Jaya, 2007) are common. One recent study (Wang et al., 2014) equated a $2^{\circ} \mathrm{C}$ temperature rise in soil temperature above temperate conditions to a $21 \%$ increase in heterotrophic respiration rate. At the high soil temperatures experienced at the tropics this represents a considerable additional driver of peat loss and consolidation. Consequently, the application of empirical consolidation models derived from antibacterial treated temperate peatland settings is considered inappropriate and not recommended within a tropical setting.

\subsubsection{Peatland hydrology}

Hydrology within tropical peatlands is little understood particularly in regard to the subsurface (Baird et al., 2017; Kelly et al., 2014). Although there have been a number of attempts to model temperate peatland hydrology (Ballard et al., 2011; Phillip Guertin et al., 1987), many studies in tropical settings have been limited to a quantification of vertical flow in relation to oxidation and soil respiration risk (Carlson et al., 2015). A surprising feature of tropical peat is its high hydrological conductivity compared to temperate peats (Baird et al., 2017; Kelly et al., 2014). In undisturbed peatlands this is not accompanied by rapid drainage due to the low hydrological gradients from the centre of the peat dome to the edge (Baird et al., 2017). This more permeable structure and higher hydrological conductivities means that the peatland is more interconnected making it much more vulnerable to regional changes in hydrology associated with construction.

One of the key tenets of peat settlement mitigation is that the hydrology of a site is unaffected by the consolidation works carried out (FCE and SNH, 2010; MacCulloch, 2006; Munro, 2005; Munro and MacCulloch, 2006). This is generally taken to mean maintenance of water table at a certain point related to the new peat surface. However, this is a paradox, as the act of loading a peatland irrevocably alters the hydrology of the immediate and surrounding areas of construction, particularly at the scale of large infrastructure projects. Peatland hydrology is complex and the disruption of flow throughout the peat can lead to pooling upstream of the development and desiccation down.

The act of pre-loading has a number of potential impacts. One such impact (potentially as seen at KLIA) is the effect of increasing the hydraulic gradient from the centre of the peat dome to the edge. The act of artificially augmenting hydraulic gradient leads to increased drainage, deepening of water tables and resulting in higher rates of oxi- 
dation (Baird et al., 2017). The addition of vertical drainage and more porous building fill may exacerbate this problem providing conduits for water flow, causing falling water tables, desiccation and oxidation in both underlying peat deposits and peatland wide. This in turn has been shown to enhance degradation and reduce the fibre content, potentially weakening underlying peat and resulting in further consolidation. After consolidation and oxidation, permeability in tropical peat unexpectedly remains high (Baird et al., 2017) meaning drainage should be expected over the long-term. This fits well with observations of settlement 30 years after initial drainage (Hooijer et al., 2012) and implies the impact of ground improvement works extends long after construction is completed.

The role of trapped gas on peat stability is also little understood particularly within saturated parts of the peat. The expulsion of gas from unsaturated parts of the peat is accounted for in many construction methodologies and is assumed to migrate laterally to adjacent areas (Huat et al., 2014). However later gas generation as a result of oxidation in compressed peat is little understood, particularly in its interaction with hydrology and under consolidation. To reflect that peat is a multiphase system containing solids (fibre, $\mathrm{OM}$ ), liquids (water) and gas $\left(\mathrm{CO}_{2}, \mathrm{CH}_{4}\right)$ mechanical models also need to be multi-dimensional and multiphase.

\subsubsection{Carbon emissions}

Another omission from much of the literature is in the carbon emissions released as a consequence of ground improvement measures. Carbon loss due to oxidation of underlying peat from large infrastructure projects over the short and medium term, particularly in the tropics is unknown. Where present in temperate settings these tend to cover either small footprint wind turbine foundations (Smith et al., 2014) or total loss in oil sands development (Rooney et al., 2012). When peat is removed and replaced by an incompressible substrate this is a fairly simple procedure, assuming total loss through peat carbon content and volume removed (Smith et al., 2014). Piling has been suggested (Smith et al., 2014) as a low carbon alternative to replacement as it appears to produce stable structures over peatland soils, and involves relatively small amounts of peat removal, and loading (other than during the construction phase; (Tomlinson and Woodward, 2014). Unfortunately this is expensive (Munro and MacCulloch, 2006).

The emission effects of loading and vertical drainage in peatlands have not been quantified. Clearly in the case of KLIA2, decomposition in addition to consolidation is occurring and producing associated carbon emissions. Although these have not been quantified for this consolidation technique, it has some similarity with the approach used during the preparation of land for oil palm plantations whose emissions have been extensively measured. In support of this the InSAR image shows similar patterns of deformation in adjacent oil palm plantations. Oil palm plantations also show consistently high levels of oxidative loss and settlement in the range reported at the KLIA2 site with $4.5 \mathrm{~cm}-50 \mathrm{~cm}$ / year (Hooijer et al., 2012) vs. $3.6 \mathrm{~cm}-24 \mathrm{~cm} /$ year (Yap, 2015). Emissions data from oil palm plantations adjacent to KLIA 2 (Matysek et al., 2017) report high heterotrophic carbon fluxes (65 and $79 \mathrm{Mg} \mathrm{CO}_{2}$ $\mathrm{ha}^{-1} \mathrm{yr}^{-1}$ ). If reproduced at KLIA2, construction related carbon emissions from peatland may relate to a sizeable additional source of carbon to the atmosphere.

\section{Conclusions}

In conclusion, we have shown the ability to use the ISBAS method to monitor the differing settlement characteristics of three peat mitigation strategies (removal and replacement, piling and preloading and vertical drainage). In addition, ISBAS offers the opportunity to examine the regional effects of construction over rural areas, areas previously not covered by InSAR. This shows that the effects of preloading and vertical drainage may not be confined to the site in which they are utilised but may compromise the hydrology of surrounding peatland. The examination of the problems experienced at KLIA and the tropical peat literature show that there is a need to tailor empirical models to the very different conditions experienced within tropical peatlands. This particularly true in studies of consolidation where oxidation (decomposition) is a factor. This also has effects on the carbon emissions from such projects and further work is required to quantify this.

\section{Uncited references}

Gee et al., 2017

Google Earth, v, 2017

\section{Acknowledgements}

This work was supported by the Engineering and Physical Sciences Research Council( and the University of Nottingham School of Biosciences Research Accelerator Award. Many thanks to the editor and two anonymous reviewers for their constructive comments allowing the improvement of the initial manuscript. Thanks are also due to Henk Pieter Sterk, Martha Ledger and Geomatic Ventures Ltd. for assistance in preparing Sentinel I data for ISBAS processing and analysis.

\section{References}

Alshammari, L., Large, D.J., Boyd, D.S., Sowter, A., Anderson, R., Andersen, R., Marsh, S., 2018. Long-term peatland condition assessment via surface motion monitoring using the ISBAS DInSAR technique over the flow country, Scotland. Remote Sens. 10 (7), 1103.

Baird, A.J., Low, R., Young, D., Swindles, G.T., Lopez, O.R., Page, S., 2017. High permeability explains the vulnerability of the carbon store in drained tropical peatlands. Geophys. Res. Lett. 44 (3), 1333-1339.

Ballard, C.E., McIntyre, N., Wheater, H.S., Holden, J., Wallage, Z.E., 2011. Hydrological modelling of drained blanket peatland. J. Hydrol. 407 (1), 81-93.

Bateson, L., Cigna, F., Boon, D., Sowter, A., 2015. The application of the Intermittent SBAS (ISBAS) InSAR method to the South Wales Coalfield, UK. Int. J. Appl. Earth Obs. Geoinf. 34, 249-257.

Carlson, K.M., Goodman, L.K., May-Tobin, C.C., 2015. Modeling relationships between water table depth and peat soil carbon loss in Southeast Asian plantations. Environ. Res. Lett. 10 (7), 074006.

Carlsten, P., 1988. Geotechnical Properties and Up-to-Date Methods of Design and Construction. Varia No.215 Swedish Geotechnical Institute.

Carlsten, P., 1989. Vägbyggnad på Torv.

Carlsten, P., 2000. Geotechnical Properties of some Swedish peats, 13th NGM -2000. Nordiska Geoteknikermötet, Helsinki, 51-60.

Chen, C.W., Zebker, H.A., 2001. Two-dimensional phase unwrapping with use of statistical models for cost functions in nonlinear optimization. J. Opt. Soc. Am. A 18 (2), 338-351.

Cigna, F., Sowter, A., 2017. The relationship between intermittent coherence and precision of ISBAS InSAR ground motion velocities: ERS-1/2 case studies in the UK. Remote Sens. Environ.

Copernicus, 2017. Copernicus Sentinel Data 2014-2017. In: https://scihub.copernicus.eu/

Crosetto, M., Monserrat, O., Iglesias, R., Crippa, B., 2010. Persistent scatterer interferometry. Photogramm. Eng. Remote Sens. 76 (9), 1061-1069.

Crosetto, M., Monserrat, O., Cuevas-González, M., Devanthéry, N., Crippa, B., 2016. Persistent scatterer interferometry: a review. ISPRS J. Photogramm. Remote Sens. 115, $78-89$

Cuenca, M.C., Hanssen, R., 2008. Subsidence due to peat decomposition in the Netherlands, kinematic observations from radar interferometry. In: Proc. Fringe 2007 Workshop. pp. 1-6.

Dykes, A.P., Warburton, J., 2007. Significance of geomorphological and subsurface drainage controls on failures of peat-covered hillslopes triggered by extreme rainfall. Earth Surf. Process. Landforms 32, 1841-1862.

FCE and SNH, 2010. Floating Roads on Peat. Scottish Natural Heritage, Inverness.

Ferretti, A., Fumagalli, A., Novali, F., Prati, C., Rocca, F., Rucci, A., 2011. A new algorithm for processing interferometric data-stacks: SqueeSAR. IEEE Trans. Geosci. Remote Sens. 49, 3460-3470.

Gee, D., 2016. Validation of the Intermittent SBAS (ISBAS) DInSAR Algorithm Over the Gas Reservoirs of North Holland. University of Nottingham, Nottingham, The Netherlands.

Gee, D., Sowter, A., Novellino, A., Marsh, S., Gluyas, J., 2016. Monitoring land motion due to natural gas extraction: Validation of the Intermittent SBAS (ISBAS) DInSAR algorithm over gas fields of North Holland, the Netherlands. Mar. Pet. Geol. 77, 1338-1354.

Gee, D., Bateson, L., Sowter, A., Grebby, S., Novellino, A., Cigna, F., Marsh, S., Banton, C., Wyatt, L., 2017. Ground motion in areas of abandoned mining: application of the 
intermittent SBAS (ISBAS) to the Northumberland and Durham Coalfield, UK. Geosciences. 7 (3), 85.

Global Forest Watch, 2017. Land Cover South East Asia. Global Forest Watch http: $/ /$ commodities.globalforestwatch.org $/ \# \mathrm{v}=$ map\&lyrs $=\mathrm{tcc} \% 2$ CldcoverAsia\& $\mathrm{x}=101$. $41 \& \mathrm{y}=2.69 \& \mathrm{l}=10$.

Hobbs, N.B., 1986. Mire morphology and the properties and behaviour of some British and foreign peats. Q. J. Eng. Geol. Hydrogeol. 19 (1), 7-80.

Holmes, O., 2015. Airline Complains of 'Sinking' Terminal at Kuala Lumpur Airport. The Guardian, London.

Hooijer, A., Page, S., Jauhiainen, J., Lee, W.A., Lu, X.X., Idris, A., Anshari, G., 2012. Subsidence and carbon loss in drained tropical peatlands. Biogeosciences 9 (3), 1053-1071.

Hooijer, A., Vernimmen, R., Mawdsley, N., Page, S., Mulyadi, D., Visser, M., 2015. Assessment of Impacts of Plantation Drainage on the Kampar Peninsula Peatland, (Riau).

Hooper, A.J., 2008. A multi-temporal InSAR method incorporating both persistent scatterer and small baseline approaches. Geophys. Res. Lett. 35 (16)https://doi.org/10. 1029/2008GL034654.

Huat, B.B.K., Prasad, A., Asadi, A., Kazemian, S., 2014. Soil improvement and construction methods in peat. In: Geotechnics of Organic Soils and Peat. CRC Press, pp. 121-169.

Jauhiainen, J., Kerojoki, O., Silvennoinen, H., Limin, S., Vasander, H., 2014. Heterotrophic respiration in drained tropical peat is greatly affected by temperature-a passive ecosystem cooling experiment. Environ. Res. Lett. 9 (10), 105013.

Jaya, A., 2007. Ecological Planning of Tropical Peatland for Carbon and Water Conservation. University of Nottingham, United Kingdom.

Jiang, L., Lin, H., 2010. Integrated analysis of SAR interferometric and geological data for investigating long-term reclamation settlement of Chek Lap Kok Airport, Hong Kong. Eng. Geol. 110 (3-4), 77-92.

JNCC, 2011. Towards an Assessment of the State of UK Peatlands.

Kelly, T.J., Baird, A.J., Roucoux, K.H., Baker, T.R., Honorio Coronado, E.N., Ríos, M., Lawson, I.T., 2014. The high hydraulic conductivity of three wooded tropical peat swamps in northeast Peru: measurements and implications for hydrological function. Hydrol. Process. 28 (9), 3373-3387.

MacCulloch, F., 2006. Guidelines for the Risk Management of Peat Slips on the Construction of Low Volume/Low Cost Roads Over Peat. ROADEX II, Inverness.

Matysek, M., Evers, S., Kana Samuel, M., Sjogersten, S., 2017. High heterotrophic CO2 emissions from a Malaysian oil palm plantations during dry-season. Wetlands(In Press).

Mesri, G., Ajlouni, M., 2007. Engineering Properties of Fibrous Peats. J. Geotech. Geoenviron. 133 (7), 850-866.

Mesri, G., Stark, T.D., Ajlouni, M.A., Chen, C.S., 1997. Secondary compression of peat with or without surcharging. J. Geotech. Geoenviron. 123 (5), 411-421.

Milillo, P., Riel, B., Minchew, B., Yun, S.H., Simons, M., Lundgren, P., 2016. On the synergistic use of SAR constellations; data exploitation for earth science and natural hazard response. IEEE J. Sel. Top. Appl. Earth Obs. Remote Sens. 9 (3), 1095-1100.

Morishita, Y., Hanssen, R.F., 2015. Temporal decorrelation in L-, C-, and X-band satellite radar interferometry for pasture on drained peat soils. IEEE Trans. Geosci. Remote Sens. 53 (2), 1096-1104.

Morris, H., 2015. Kuala Lumpur's klia2 terminal is sinking, says airline. The Telegraph, London.
Motagh, M., Shamshiri, R., Haghshenas Haghighi, M., Wetzel, H., Akbari, B., Nahavandchi, H., Roessner, S., Arabi, S., 2017. Quantifying groundwater exploitation induced subsidence in the Rafsanjan plain, southeastern Iran, using InSAR time-series and in situ measurements. Eng. Geol. 218, 134-155. https://doi.org/10.1016/j.enggeo.2017. 01.011.

Munro, R., 2005. Dealing With Bearing Capacity Problems on Low Volume Roads Constructed on Peat. ROADEX II, Inverness.

Munro, R., MacCulloch, F., 2006. Managing Peat Related Problems on Low Volume Roads Executive Summary. Roadex III, Luleå.

Osmanoglu, B., Sunar, F., Wdowinski, S., Cabral-Cano, E., 2015. Time series analysis of InSAR data: methods and trends. ISPRS J. Photogramm. Remote Sens. 115, 90-102.

Page, S.E., Rieley, J.O., Banks, C.J., 2011. Global and regional importance of the tropical peatland carbon pool. Glob. Chang. Biol. 17 (2), 798-818.

Peduto, D., Nicodemo, G., Maccabiani, J., Ferlisi, S., 2017. Multi-scale analysis of settlement-induced building damage using damage surveys and DInSAR data: A case study in The Netherlands. Eng. Geol. 218, 117-133.

Phillip Guertin, D., Barten, P.K., Brooks, K.N., 1987. The peatland hydrologic impact model: development and testing. Hydrol. Res. 18 (2), 79-100.

Radforth, N.W., 1969. The Muskeg Engineering Handbook. National Research Council of Canada.

Rooney, R.C., Bayley, S.E., Schindler, D.W., 2012. Oil sands mining and reclamation cause massive loss of peatland and stored carbon. Proc. Natl. Acad. Sci. U. S. A. 109 (13), 4933-4937.

Samson, L., Rochelle, P.L., 1972. Design and performance of an expressway constructed over peat by preloading. Can. Geotech. J. 9 (4), 447-466.

Smith, J., Nayak, D.R., Smith, P., 2014. Wind farms on undegraded peatlands are unlikely to reduce future carbon emissions. Energy Policy 66 (Supplement C), 585-591.

Sowter, A., Bateson, L., Strange, P., Ambrose, K., Syafiudin, M.F., 2013. DInSAR estimation of land motion using intermittent coherence with application to the South Derbyshire and Leicestershire coalfields. Remote Sens. Lett. 4 (10), 979-987.

Sowter, A., Bin Che Amat, M., Cigna, F., Marsh, S., Athab, A., Alshammari, L., 2016. Mexico City land subsidence in 2014-2015 with Sentinel-1 IW TOPS: results using the Intermittent SBAS (ISBAS) technique. Int. J. Appl. Earth Obs. Geoinf. 52, 230-242.

Sowter, A., Athab, A., Novellino, A., Grebby, S., Gee, D., 2018. Supporting energy regulation by monitoring land motion on a regional and national scale: A case study of Scotland. Proc. IMechE A

Tomlinson, M., Woodward, J., 2014. General principles and practices. In: Pile Design and Construction Practice, Sixth edition CRC Press, pp. 1-10.

Von Post, L., 1922. Sveriges Geologiska Undersøkings torvinventering och nogra av dess hittils vunna resultat. Sveriges Geologiska Undersøkings, Jønkøping, Sweden.

Wang, X., Liu, L., Piao, S., Janssens, I.A., Tang, J., Liu, W., Chi, Y., Wang, J., Xu, S., 2014. Soil respiration under climate warming: differential response of heterotrophic and autotrophic respiration. Glob. Chang. Biol. 20 (10), 3229-3237.

Warburton, J., Holden, J., Mills, A.J., 2004. Hydrological controls of surficial mass movements in peat. Earth Sci. Rev. 67 (1), 139-156.

World Bank, 2017. CO2 Emissions (kt) Malaysia 1998. In: https://data.worldbank.org/ indicator/EN.ATM.CO2E.KT?locations $=$ MY.

Wösten, J.H.M., Ismail, A.B., van Wijk, A.L.M., 1997. Peat subsidence and its practical implications: a case study in Malaysia. Geoderma 78 (1-2), 25-36.

Yap, R., 2015. Coming Clean on KLIA2 Sinking. CIMB, Malaysia. 